\title{
Educação, empregabilidade e mobilidade social: convergências e divergências
}

\author{
Education, employabilitiy and social mobility: divergences and convergences
}

\author{
Ana Heloisa da Costa Lemos ${ }^{1}$ \\ Veranise Jacubowski Correia Dubeux $x^{2}$ \\ Mario Couto Soares Pinto ${ }^{3}$
}

\section{Resumo}

A qualificação profissional tem sido alardeada como um diferencial para a inserção no mercado de trabalho dos egressos de cursos de graduação. Com base em premissas típicas da teoria do capital humano, considera-se $o$ investimento em educação estratégico para impulsionar a ascensão social dos indivíduos e potencializar 0 crescimento econômico da sociedade. Todavia, a análise do estudo de Bourdieu (1988) acerca da mobilidade social da sociedade francesa na década de 1970 leva ao questionamento dessa suposta relação causal entre formação e empregabilidade, na medida em que revela outros vetores que influenciam a ascensão social dos indivíduos. Segundo o autor, as classes econômica e culturalmente mais favorecidas oferecem mais acessos a posições de maior potencial no mercado de trabalho a seus descendentes do que as da base do estrato social. Esta investigação teve como objetivo testar a validade das proposições de Bourdieu, a partir de uma pesquisa feita com 98 formandos e egressos de um curso de administração de empresas de uma renomada IES do Rio de Janeiro. Como conclusão, foi possível identificar relações entre as origens desses egressos e sua inserção no mercado de trabalho, ligando a bagagem cultural e econômica de sua família, às empresas e aos postos aos quais ascenderam.

Palavras-chave: mobilidade social; qualificação profissional; empregabilidade.

\section{Abstract}

Professional qualification has been considered one of the most important competitive advantages for those people that want to get on the labour market, after finishing an undergraduate course. Based on the typical assumptions of human capital theory, the investments in education are usually perceived as strategic to push up one's social position and also to support society's economic growth. However, Bourdieu's study about social mobility (BOURDIEU, 1980) in French Society in the 1970's brought some questioning about the direct relationship between the required skills in an undergraduate program with the capability to keep one's jobs. As mentioned by the author, the higher the economical and cultural status one social class has, the better opportunities will be made available in the labour market in the future. In other words, those at the bottom of the social pyramid have a tougher situation in finding better opportunities. This research's goal is to verify such a hypothesis, by means of a survey with 98 students that are concluding or have just concluded a business undergraduate program in a well known university in Rio de Janeiro, Brazil. As a result, it was possible to determine a relationship between the social and economical background of those interviewed and their

\footnotetext{
${ }^{1}$ Doutora em Sociologia pelo IUPERJ. Professora do quadro principal da PUC-Rio.Endereço: Rua Marques de São Vicente 225 - Gávea - Rio de Janeiro/RJ Brasil -CEP: 22451900 - Email: ah.lemos@uol.com.br

${ }^{2}$ Doutora em Engenharia Mecânica pela COPPE/UFRJ. Professora da Pontifícia Universidade Católica do Rio de Janeiro - PUC-Rio e da Escola Superior de Propaganda e Marketing - ESPM-Rio; Pesquisadora do Centro de Altos Estudos de Propaganda e Marketing da ESPM-SP.Endereço: Rua Marques de São Vicente, 225 - Gávea - Brasil - CEP: 22451-041. E-mail: veranise.dubeux@uol.com.br

${ }^{3}$ Doutor em Administração pela Pontifícia Universidade Católica - PUC-Rio. Professor do Mestrado em Administração Empresarial da Universidade Estácio de Sá (MADE/UNESA). Endeeço: Av. Presidente Vargas, 642 / 220. andar - Rio de Janeiro - RJ - Brasil - CEP: 20071-001. E-mail: mpinto@iag.puc-rio.br

Artigo submetido em setembro e aceito em novembro de 2008
} 
professional career, putting together the cultural and economical background of their family as well as the jobs they had in the companies that hired them.

Keywords: social mobility; professional qualification; employability.

\section{Introdução}

No decorrer das últimas décadas observou-se que a questão da qualificação profissional - entendida como requisito da empregabilidade - vem se constituindo como importante desafio a ser enfrentado pelos profissionais que pretendem se inserir no mercado de trabalho. $\mathrm{O}$ debate acerca das transformações em curso no mundo do trabalho tem sido pautado pela ênfase nos novos perfis profissionais que passam a ser requeridos nesse novo contexto.

É importante ressaltar que o atual processo de valorização da formação profissional como estratégia de enfrentamento do desemprego que se difunde no Brasil é reflexo, em grande medida, do debate internacional acerca da crise do mercado de trabalho. A ênfase na melhoria da qualificação da força de trabalho é parte importante das estratégias de enfrentamento do desemprego adotadas por países da União Européia, tal como a Alemanha, Suécia, Inglaterra, Espanha, Itália, França e Holanda - ainda que não seja a única estratégia em foco - (DEDECCA, 1998; GRAZIER, 1990), além de ser recomendada por organismos internacionais como a Organização Internacional do Trabalho (OIT, 1999) e o Banco Mundial, com o mesmo objetivo. Essa valorização reflete a ascensão de políticas de orientação liberal, conformando um terreno fértil para a retomada de pressupostos da teoria do capital humano.

Nesse contexto, o papel econômico da educação é revalorizado, ainda que em bases diferentes do ocorrido na década de 1960, quando era associada ao crescimento econômico e à integração social dos indivíduos. A partir da crise do capitalismo avançado, a educação passa a desempenhar novo papel, sendo chamada não mais a promover o desenvolvimento econômico (conforme preconizava a teoria do capital humano), mas a aumentar as chances individuais de inserção no mercado de trabalho ou, em outros termos, a aumentar a empregabilidade dos indivíduos, num cenário em que o desemprego tecnológico parece que veio para ficar (CASTELLS, 1999).

Apesar da crescente valorização da qualificação profissional, considerada requisito-chave para a inserção no mercado de trabalho, pesquisa recente feita por Ramos (2006) indica que um contingente expressivo de trabalhadores brasileiros mais escolarizados não consegue obter ocupações à altura de suas qualificações. De acordo com a referida pesquisa, o desemprego afeta de forma mais intensa indivíduos que, apesar da elevada escolaridade (curso superior completo), são oriundos de estrato social menos favorecido. Segundo o pesquisador, o desemprego entre os mais pobres é 17 vezes maior do que entre os mais ricos, com o mesmo nível de estudo. $\mathrm{O}$ contraste entre os resultados da pesquisa e a mencionada valorização da formação profissional enseja a indagação quanto ao impacto da qualificação na empregabilidade do indivíduo. Será a qualificação profissional um elemento decisivo para a obtenção de emprego/trabalho ou essa é apenas mais um requisito para a empregabilidade, porém subordinada em importância à origem social de seu detentor? Ademais, chama atenção para elementos importantes, porém menos objetivos, que também afetam a empregabilidade dos trabalhadores: a origem social e a rede de relacionamentos. De acordo com Ramos, o "berço" é fundamental para garantir a inserção no mercado de trabalho, mas isso não significa que a educação não seja relevante no que tange à empregabilidade.

O impacto da origem social no aumento das chances de inserção no mercado de trabalho, revelado na pesquisa citada, vai ao encontro de constatações feitas por Bourdieu (1988), na década de 1970, que dizem respeito às condições estruturais que reproduzem as posições de classe na sociedade capitalista. Em A distinção, Bourdieu (1988) apresenta não só as estratificações sociais da sociedade contemporânea, mas aborda também os 
mecanismos sociais que reproduzem essas estratificações. Ao destacar que as chances daqueles nascidos no seio das elites socioculturais da sociedade se manterem nessa condição em sua vida adulta são tão grandes quanto as chances dos filhos dos menos favorecidos reproduzirem as condições de vida de seus pais, no futuro, Bourdieu ressalta a dimensão estrutural da condição de inserção social, que relega ao segundo plano a possibilidade dos esforços individuais romperem as fronteiras de classes.

Tendo como pano de fundo o estudo de Bourdieu, os resultados da pesquisa supracitada (RAMOS, 2006) e o debate acerca da qualificação como determinante da empregabilidade adquirem novos tons. Torna-se relevante investigar se as chances de inserção do indivíduo no mercado de trabalho são potencializadas por sua qualificação profissional ou por sua origem social, ou se, de alguma forma, esta influencia aquela. Como decorrência, é plausível questionar se a contratação de novos trabalhadores baseia-se exclusivamente em critérios meritocráticos ou se elementos "aristocráticos" são também levados em consideração. O aparente anacronismo da questão - falar em aristocracia em um estágio avançado do capitalismo - reforça a curiosidade quanto ao tema. Afinal, será que, em plena sociedade do conhecimento, o "berço" ainda é um fator decisivo para a inclusão dos indivíduos no mercado de trabalho e, por extensão, na sociedade? Ou será que indivíduos qualificados conseguem romper eventuais barreiras sociais e conquistar vagas disputadas no mercado de trabalho?

Com o objetivo de esboçar respostas a essas indagações foi realizado, entre março e abril de 2008, um levantamento em que se buscou investigar as condições de inserção no mercado de trabalho de formandos e egressos do curso de administração de empresas de uma instituição de ensino superior privada (IES), do Rio de Janeiro. Tendo como base dados obtidos por meio de questionário aplicado eletronicamente, o referido levantamento procurou relacionar a inserção no mercado de trabalho do entrevistado com seu perfil socioeconômico, visando discutir, à luz da amostra pesquisada, em que medida a tese de Bourdieu sobre a reprodução das desigualdades sociais está refletida no universo analisado. Dado que todos os entrevistados têm formação superior completa ou em fase de conclusão em uma conceituada IES, procurou-se investigar uma eventual relação entre os estratos econômicos de origem desses indivíduos e as características de seu estágio ou emprego, sendo considerado, para essa análise, o tipo de empresa e a remuneração. Entendeu-se que a possível convergência dos indicadores de emprego de melhor qualidade e origem socioeconômica privilegiada, por um lado, e o emprego de qualidade inferior e origem socioeconômica menos privilegiada, por outro, em uma amostra de indivíduos com a mesma formação profissional, poderia ser interpretada como um reforço à tese de Bourdieu. Sem a pretensão de apresentar evidências definitivas à questão da reprodução das desigualdades sociais, este estudo procurou explorar a relação entre a empregabilidade de jovens, vis-à-vis sua origem socioeconômica.

\section{Da teoria do capital humano à sociedade do conhecimento}

A preocupação atual com a qualificação da força de trabalho encontra ressonância na valorização que o campo educacional passou a receber após a II Guerra Mundial, no contexto que combinou criação do Welfare State com a crença na capacidade da educação de contribuir para a construção de "personalidades democráticas", em um mundo traumatizado pela aparição de "personalidades autoritárias" (PAIVA, 1993). Apesar da ênfase no ensino em massa remontar a meados do século XIX, foi no pós-guerra que se concretizou a maior revolução educacional da história (PAIVA, 1993).

A rápida expansão dos sistemas educacionais nas economias capitalistas e socialistas e a importância que passou a ser atribuída à educação como fator de integração social e de propulsão do desenvolvimento econômico criaram as condições para o surgimento, entre as décadas de 1950 e 1960, de uma disciplina para estudar esse fenômeno, a economia da educação, e de uma teoria capaz de explicar as relações entre educação e desenvolvimento, a teoria do capital humano. Elaborada por Schultz $(1967,1987)$ entre o final da década de 
1950 e o início dos anos 1960, essa teoria pretendeu rever os conceitos clássicos de capital e trabalho, argumentando que não se tratavam de fatores imutáveis, pois o trabalho podia configurar-se em recurso maleável, capaz de fazer crescer a economia, na medida em que se valorizava, mediante investimentos em educação.

A proposição fundamental de Schultz é que, por intermédio do investimento em educação, as pessoas valorizam suas capacidades e as habilitações adquiridas exercem influência sobre os padrões de acumulação de poupanças e formação de capitais, além de alterarem as estruturas de pagamentos e salários e os totais de ganhos decorrentes do trabalho relativo ao montante do rendimento da propriedade. De forma simplificada, a educação é vista como um investimento que eleva a produtividade e os lucros dos trabalhadores, além de impulsionar o desenvolvimento econômico.

Formulado durante os anos de crescimento econômico, o conceito de Schultz forneceu uma explicação para as diferenças de desenvolvimento entre as nações capitalistas e rendimentos entre os indivíduos: os diferentes estoques de capital educacional justificariam essas diferenças, constituindo-se em receituário para a saída do subdesenvolvimento. Dessa forma,

O processo de escolaridade era interpretado como um elemento fundamental na formação do capital humano necessário para garantir a capacidade competitiva das economias e, conseqüentemente, o incremento progressivo da riqueza social e da renda individual. (GENTILI, 2001, p.80)

Criticada por abordagens de orientação marxista, essa teoria veio a perder parte de seu apelo nas décadas de 1970 e 1980 sem, contudo, perder vigência. Desde finais da década de 1980, os efeitos da reestruturação produtiva no contingente de empregos disponíveis deram fôlego novo à referida teoria.

Após período de relativo ostracismo, a teoria do capital humano voltou a ocupar lugar central nas discussões sobre desemprego, qualidade dos postos de trabalho e crescimento econômico. Essa retomada acrescentou novos termos ao debate sobre o impacto da educação na vida dos indivíduos e das nações, mantendo, entretanto, o cerne do argumento de que o capital humano é o principal propulsor do desenvolvimento econômico. De acordo com Paiva, nos últimos anos

[...] uma versão mais sofisticada da economia da educação emerge no cenário acadêmico e político, ao mesmo tempo em que recuam as análises sociológicas e políticas. A educação adquire uma nova relevância perante as características e exigências decorrentes do novo paradigma produtivo. (PAIVA, 1993, p.311)

Apesar de economistas como Camargo e Almeida (1994), Ferreira (2000) e Soares e Gonzaga (1997) basearem suas análises nos pressupostos clássicos da teoria do capital humano, apostando na capacidade da educação gerar crescimento, educadores como Gentili (1999) entendem a discussão atual sobre qualificação profissional e desemprego como uma retomada dessa teoria, ainda que em termos diferentes de sua formulação original. Num contexto marcado pelo desemprego e pelo fim da promessa do pleno emprego, ao discutir o que denomina desintegração da promessa integradora da educação, Gentili (2001) adverte para a modificação do sentido econômico a esta atribuído. Incapaz de assegurar a inserção no mercado de trabalho e a melhoria das condições de vida de todos, o investimento em educação e na formação profissional apenas aumentaria as chances de inserção no mercado de trabalho.

É nessas novas bases que a teoria do capital humano é apropriada pelo discurso que atualmente valoriza a qualificação profissional. Entendem os autores que a expressão "sociedade do conhecimento" atualiza a teoria do capital humano, delineando as exigências de qualificação e formação humana a partir dos conceitos de qualidade total, trabalho participativo em equipe, formação flexível, abstrata e polivalente. Mas, se é verdade que a produção informatizada e automatizada requer novas habilidades à força de trabalho, segundo Frigotto 
(2001c) essas novas exigências não se dirigem ao universo da classe trabalhadora, mas a uma elite a qual estariam destinados os trabalhos estáveis e de qualidade.

O conceito de sociedade do conhecimento, utilizado por Drucker (1999) e por Toffler (1998), enfatiza a importância da força de trabalho, na medida em que esta consiga combinar polivalência, flexibilidade, iniciativa, capacidade de abstração e decisão, requisitos demandados pelas empresas que passam por processo de reconversão tecnológica. A percepção de autores como Gentili (1999, 2001) e Frigotto (2001a, 2001b, 2001c) é que, longe de representar uma evolução da teoria do capital humano, o conceito sociedade do conhecimento implica a intensificação da exploração da força de trabalho, que deve moldar integralmente sua qualificação às necessidades do setor produtivo.

De forma conclusiva, pode-se postular que as premissas subjacentes à teoria do capital humano sustentam a valorização que a qualificação profissional vem recebendo no Brasil nos últimos anos. Enfatiza-se a idéia de que o investimento em educação, ao aumentar a qualidade da força de trabalho, propicia ganhos de produtividade e aumento da criação de empregos de melhor qualidade, o que conduz ao crescimento econômico. A percepção de que a educação é um investimento e que a capacidade produtiva do trabalho é, em grande medida, um meio de produção produzido - "Nós produzimos a nós mesmos" (SCHULTZ, 1967, p.25) - reforça a preocupação com a qualificação do trabalhador, entendida esta como potencializadora do crescimento econômico. Entende-se que a educação aumentaria as chances individuais de acesso aos postos de trabalho, num cenário em que esses são cada vez mais escassos. O capital educacional acumulado pelo trabalhador asseguraria não só sua maior produtividade, como explicaria as diferenças individuais de oportunidades de inserção no mercado e de remuneração recebida.

Premidos pela competição acirrada por postos de trabalho, indivíduos procuram investir recursos crescentes, com vistas à melhoria de sua formação profissional, na esperança de aumentar sua empregabilidade. Cabe indagar, no entanto, se esse investimento efetivamente garante maior competitividade a seus detentores, independente de sua origem social, ou se resulta em uma promessa que se apresenta de forma desigual a seus possuidores: real, para aqueles que combinam uma melhor qualificação profissional com atributos que remetem à sua origem socioeconômica, ou ilusória, para aqueles cujo único diferencial é uma formação de melhor qualidade.

\section{Bourdieu e a reprodução das desigualdades sociais}

Em seu clássico estudo sobre as bases sociais do gosto, Bourdieu (1988) ressalta as condições estruturais que reproduzem as desigualdades sociais. Ao localizar os diferentes estratos sociais a partir de sua maior ou menor detenção dos capitais cultural e/ou econômico, o autor amplia a visão acerca da estratificação social da sociedade capitalista. Tendo como base extensa pesquisa realizada nas décadas de 1960 e 1970, na França, Bourdieu revela que a mobilidade social vertical naquela sociedade é muito mais limitada do que os estudos tradicionais sobre o tema costumam indicar. Dentre suas inúmeras conclusões de pesquisas, o autor destaca que

41,7\% dos filhos de profissionais liberais e 38,9\% dos filhos de engenheiros, de funcionários administrativos superiores ou médios ou de técnicos de empresas ocupam postos administrativos e de direção geral diante de $25,7 \%$ do conjunto. Pelo contrário, 47,9\% dos filhos de operários qualificados, 43,8\% dos filhos de contramestres e 41,1\% dos filhos de técnicos cumprem funções de produção, de fabricação ou de manutenção ante 29,7\% do conjunto. Sabe-se também que os quadros superiores originários de famílias de empregados recebiam em 1962 um salário anual médio de 18.027 francos comparado a 29.470 francos para os filhos de industriais ou de grandes comerciantes; os engenheiros filhos de assalariados agrícolas e de agricultores autônomos recebiam 20.227 francos 
comparados a 31.388 francos para os filhos de industriais e de grandes comerciantes. (BOURDIEU, $1988, p .133)$

Com esses e outros resultados de pesquisa, Bourdieu reforça sua tese de que os filhos dos detentores de maior capital econômico ou cultural tendem a reproduzir essas heranças, da mesma forma que os filhos dos possuidores de menor capital têm menores chances de aumentarem seu capital, seja cultural ou econômico.

Esse efeito também pode ser discutido à luz do debate acerca das "vocações" (BOURDIEU, 1988, p.134). Para esse autor, os filhos das elites econômica e cultural direcionam-se, em sua maioria, para carreiras universitárias e para o gerenciamento dos negócios da família, enquanto os filhos de trabalhadores pouco qualificados direcionam suas aspirações profissionais para carreiras que requerem menor qualificação. Em outros termos, a posição social do indivíduo condiciona, em grande medida, suas disposições; as trajetórias profissionais individuais tendem a ser trajetórias de classe. $\mathrm{O}$ autor destaca que, o fato de alguns indivíduos se afastarem de suas trajetórias de classe não chega a ofuscar essas trajetórias coletivas, posto que, mesmo os desviantes seguem, em certos aspectos, marcados por hábitos de sua classe de origem, por um destino coletivo.

No que diz respeito ao aumento da escolaridade e obtenção de diploma de curso superior - uma das principais expressões do capital cultural -, Bourdieu aponta a tendência dos filhos das elites detentoras de elevado capital econômico e, principalmente, os filhos das elites com maior capital cultural, obterem os maiores índices de titulação superior. $\mathrm{O}$ autor destaca, ainda, que os filhos dessas elites, além de serem líderes na obtenção dos diplomas, são também os que sofrem menos os efeitos da desvalorização dessa formação decorrente da popularização dos cursos superiores. $\mathrm{O}$ crescimento do número de bacharéis (e mesmo de detentores de diplomas do ensino médio), inclusive, aqueles oriundos de estratos menos favorecidos econômica e culturalmente, tende a desvalorizar essa formação, mas esse efeito atinge muito mais o segundo grupo do que o primeiro. No caso da França, Bourdieu atribui esse efeito à origem social do possuidor do diploma, pois "a titulação vale o que vale econômica e socialmente seu possuidor, sendo o rendimento do capital escolar condicionado pelo capital econômico e pelo capital social que podem ser dedicados a sua valorização" (BOURDIEU, 1988, p.133).

Além do capital econômico e do cultural, Bourdieu destaca também a importância do capital social, "capital de relações mundanas que podem, dependendo do caso, proporcionar 'apoios úteis', capital de honorabilidade e de respeitabilidade que é indispensável para se atrair ou assegurar a confiança da boa sociedade" (BOURDIEU, 1988, p.118). Esse capital, combinado à educação formal superior, potencializa as chances do diplomado converter a formação recebida em capital econômico. Em outros termos, aquele ativo abre portas para os bons empregos, para a boa clientela, para os bons contatos que, em última instância, permitem aos filhos das elites econômica e/ou cultural reproduzirem sua condição social.

Sem negar a importância do capital cultural como reprodutor da condição de membro das elites cultural e econômica, na medida em que esse ativo pode ser convertido em capital econômico, os argumentos de Bourdieu permitem relativizar o impacto da educação superior formal na empregabilidade de seu possuidor, dado que este tende a ser mais intenso para aqueles que detêm condições capazes de combinar os diversos tipos de capital mencionados.

As considerações de Bourdieu dão fundamento à conclusão da pesquisa inicialmente citada (RAMOS, 2006), a qual sugere que a educação formal é um recurso tanto mais eficaz quanto maior capital social e econômico possui seu detentor. Dessa forma, não seria um recurso que amplia, a priori, as chances de ascensão social de todos os seus possuidores, visto que estas seriam resultantes da combinação desse ativo com outros tipos de capital. Logo, uma formação superior em uma universidade de renome, ainda que possa abrir portas para os diplomados oriundos das classes populares, provavelmente, não abrirá as mesmas portas que se apresentam aos originários das classes dominantes. Ademais, a condição de detentor de maior capital cultural - expresso na 
obtenção de diploma de curso superior - está, segundo o autor, bastante condicionada pela origem social, pois a probabilidade de filhos das elites econômica e/ou cultural obterem esses diplomas é sensivelmente superior à probabilidade dos filhos daqueles que possuem pouco capital econômico e cultural alcançarem esse mesmo objetivo.

Apesar do estudo de Bourdieu ter como referência a sociedade francesa nas décadas de 1960 e 1970, suas conclusões permitem refletir sobre a realidade brasileira contemporânea, pois o impacto positivo do capital social e da origem familiar do detentor de diploma de curso superior na sua inserção profissional e social está longe de ser um fato alheio ao nosso contexto social.

\section{O desenho da pesquisa e seus aspectos metodológicos}

Com o intuito de analisar a pertinência das conclusões de Bourdieu vis-à-vis a realidade brasileira contemporânea, realizou-se um levantamento para mapear e analisar as condições de inserção no mercado de trabalho dos formandos (com até um ano de conclusão do curso) e egressos (cursando o último período) do curso de graduação em administração de empresas de uma IES particular. Pretendeu-se, com a análise em questão, contribuir para um entendimento mais acurado da relação entre a empregabilidade desses indivíduos e seu perfil socioeconômico.

As principais variáveis consideradas no levantamento contemplaram a condição empregatícia do formando ou egresso, a empresa em que trabalha, a faixa salarial e o perfil socioeconômico. Os diferentes cruzamentos entre essas variáveis permitiram analisar a empregabilidade dos pesquisados à luz de sua origem socioeconômica.

Para o referido levantamento aplicou-se, por meio eletrônico, um questionário fechado que visava identificar as condições de inserção do entrevistado no mercado de trabalho, seja na condição de estagiário ou de funcionário recém-contratado, bem como traçar seu perfil socioeconômico. As perguntas dos questionários foram moldadas de forma a representar ambos os eixos de análise do constructo de Bourdieu, formados pelas dimensões cultural e econômica. Foram focalizados aspectos referentes à renda individual e familiar do entrevistado, à escolaridade de seus pais, ao local de moradia, à frequiência de viagens ao exterior e ao domínio de idiomas estrangeiros, por se considerar que esses itens são indicadores relevantes da condição socioeconômica dos entrevistados.

Conforme apontado anteriormente, a pesquisa objetivou identificar uma possível correlação positiva entre a qualidade do emprego do entrevistado e sua origem socioeconômica, visando verificar a pertinência das conclusões de Bourdieu acerca da tendência estrutural à reprodução das desigualdades sociais.

A amostra foi definida por tipicidade, visto que fora constituída por elementos representativos da populaçãoalvo, sendo composta inicialmente por 98 entrevistas - entre formandos e egressos de um universo de 93 egressos e 98 formandos - e representativa da população. A expectativa inicial era de que pelo menos $50 \%$ dos entrevistados respondessem ao questionário, o que foi atingido. Os dados foram coletados em fichas individuais e armazenados em banco de dados do Excel, sendo analisados nos programas Excel e SPSS 16.0 para Windows (Microsoft Corporation).

Os dados gerados nesse processo foram analisados e tratados interpretativamente, considerando-se a hipótese de Bourdieu relativa às condições estruturais de reprodução das desigualdades sociais. No levantamento em questão, estas seriam manifestas na possível tendência dos indivíduos de maior renda familiar - privilegiados na esfera econômica - terem empregos de melhor qualidade, em empresas de médio ou grande porte e com maiores salários, do que aqueles de origem menos abonada, não obstante terem ambos a mesma formação universitária. Entendeu-se que a possível confirmação dessa tendência reforçaria a pertinência da tese de 
Bourdieu para estudar a dinâmica do universo da inserção no mercado de trabalho de egressos de cursos superiores, no Brasil.

\section{Discussão dos resultados obtidos}

Para que se desse início ao exame dos dados obtidos no levantamento foram feitos alguns filtros com o objetivo de identificar subgrupos dentro da amostra dos 98 respondentes. O filtro que apresentou melhores indicadores, à luz da hipótese em análise, foi o relacionado à renda bruta familiar. Como se pode observar na figura 1, dos 98 indivíduos, 93 responderam à pergunta relacionada à renda mensal bruta familiar, sendo possível estratificar a amostra em três grupos, a saber: com renda bruta familiar abaixo de $\mathrm{R} \$ 5.000,00$, entre $\mathrm{R} \$ 5.000,00$ e $\mathrm{R} \$ 12.000,00$ e acima de $\mathrm{R} \$ 12.000,00$. Uma vez delineados esses grupos, para efeito de investigação, optou-se por focar apenas os dois extremos - os segmentos com maior e menor renda -, pois essa distinção se coaduna com a discussão de Bourdieu que orienta esta análise. Cabe salientar, todavia, que mesmo o grupo identificado como de menor renda familiar (até $\mathrm{R} \$ 5.000,00$ ), possui renda bastante elevada para os padrões brasileiros. Esse fato decorre do viés inerente ao universo em análise: egressos de uma IES privada de renome. Apesar dessa IES oferecer bolsas de estudos integrais, permitindo que alunos com renda familiar mais baixa freqüentem seus cursos, é inevitável que os alunos com renda familiar elevada sejam majoritários. Não obstante a pesquisa investigar, em grande medida, privilegiados na esfera econômica, a análise dos extremos indicados revelou diferenças sensíveis entre os dois grupos, permitindo as considerações apresentadas adiante.

\section{Figura 1}

\section{Gráfico com a freqüência da renda mensal bruta familiar}

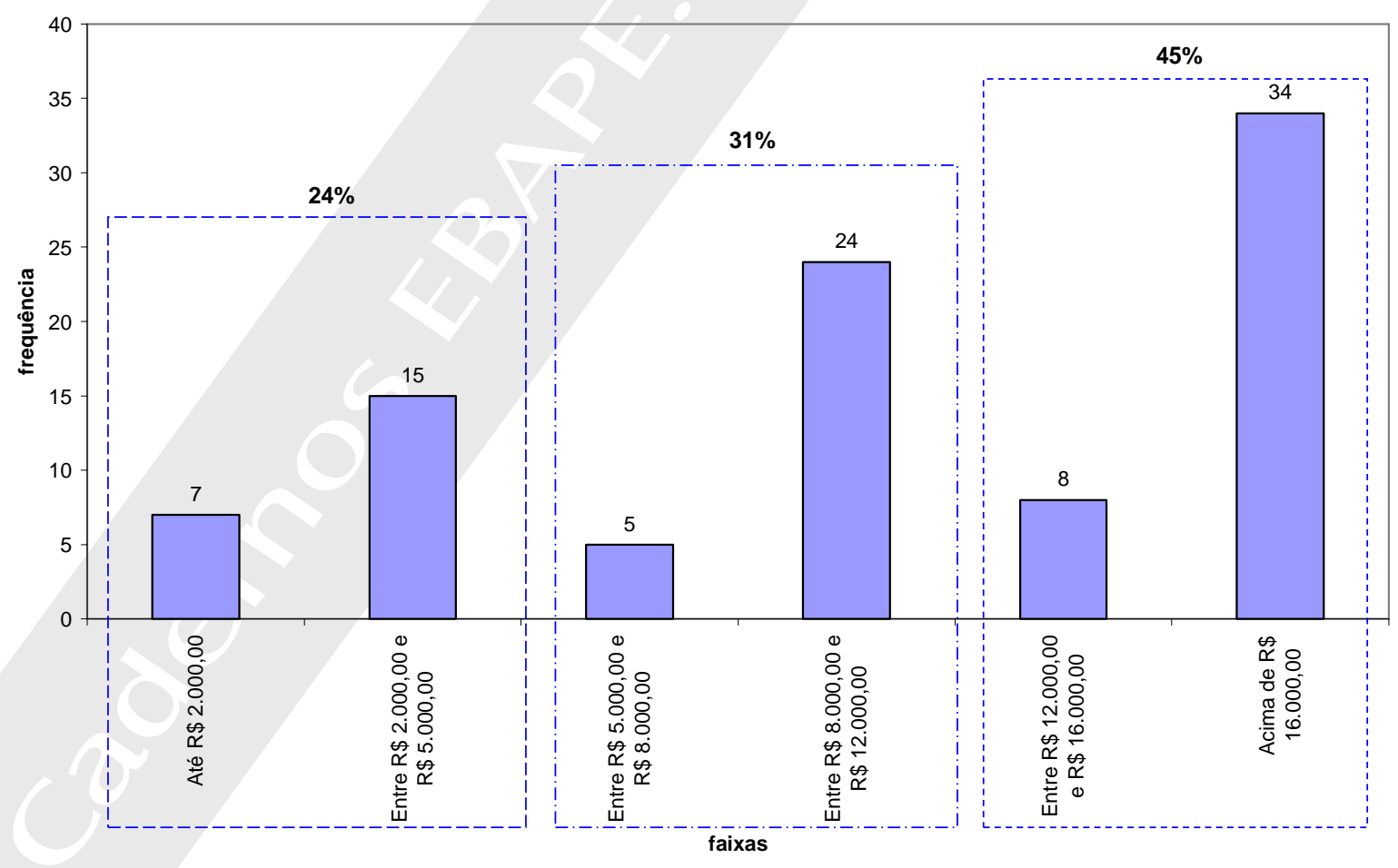

Fonte: Elaborado pelos autores. 
Ao serem analisados os dados obtidos no levantamento, e tendo como referência as conclusões de Bourdieu acerca da tendência à reprodução das desigualdades sociais, observaram-se alguns aspectos que reforçam o interesse inicial nos argumentos do autor. No que diz respeito à constatação central de suas pesquisas, a de que indivíduos oriundos de famílias com maior capital econômico tendem a reproduzir essa condição privilegiada da mesma forma que os possuidores de menor capital reproduzem sua própria condição, os dados analisados, quando interpretados à luz dessa assertiva, merecem atenção. O que se pôde constatar, ao se observar os indivíduos com maior e menor renda familiar da amostra, foi a existência de diferenças quanto às condições de inserção no mercado de trabalho. Os indivíduos com menor renda familiar (até $\mathrm{R} \$ 5.000,00$ ), além de estarem, em sua maioria, (90\%) trabalhando ou estagiando, em contraste com os respondentes de maior renda (50\% trabalhando), recebem menor remuneração e em maior número aceitam trabalhar para empresas de pequeno porte do que os do outro estrato (tabelas 1 e 2). Entre os empregados, aparecem duas exceções a essa tendência: um egresso trabalha na Sociedade Comercial e Importadora Hermes S.A., recebendo entre $\mathrm{R} \$ 4.000,00$ e $\mathrm{R} \$ 5.000,00$ (que pode ser considerada uma remuneração elevada), enquanto outro trabalha na Fundação Vale do Rio Doce de Seguridade Social, uma organização de grande porte, sem dúvida. Os demais empregados, 12 (ou 91\% do total), recebem salários entre $\mathrm{R} \$ 1.000,00$ e $\mathrm{R} \$ 3.000,00$ (tabela 2).

Tabela 1

Condição empregatícia por faixa de renda familiar

\begin{tabular}{|c|c|c|}
\hline Renda familiar & Trabalho/estágio & Freqüência \\
\hline Até $R \$ 5.000,00$ & sim & 20 \\
\cline { 2 - 3 } & não & 2 \\
\hline \multirow{2}{*}{ De $R \$ 5.000,00$ a $R \$ 12.000,00$} & sim & 20 \\
\hline Acima de $R \$ 12.000,00$ & não & 9 \\
\hline & sim & 28 \\
\hline
\end{tabular}

Fonte: Elaborada pelos autores. 
Tabela 2

Grupo de indivíduos com menor renda familiar (até $\mathbf{R} \$ 5.000,00)$

\begin{tabular}{|c|c|c|}
\hline Empresa & Função & Renda própria \\
\hline Transportadora Gasoduto Bolívia Brasil S. A. & Estagiário & Até $R \$ 1.000,00$ \\
\hline CPMBRAXIS & Estágiário & Até $R \$ 1.000,00$ \\
\hline TIM & Estágiário & Até $R \$ 1.000,00$ \\
\hline Contax & Representante de serviços & Até $R \$ 1.000,00$ \\
\hline Não informou & Não informou & Até $\mathrm{R} \$ 1.000,00$ \\
\hline Telemetria & Secretária & Entre $R \$ 1.000,00$ e $R \$ 2.000,00$ \\
\hline Casa Nossa Empreendimentos Imobiliários Ltda & Ass. administrativo & Entre $R \$ 1.000,00$ e $R \$ 2.000,00$ \\
\hline Free Lancer - Produção TV / Teatro / Exposições & Produtor & Entre $R \$ 1.000,00$ e $R \$ 2.000,00$ \\
\hline Banco BBM S.A. & Estágiário & Entre $R \$ 1.000,00$ e $R \$ 2.000,00$ \\
\hline Coloplast do Brasil & Estágiário & Entre $R \$ 1.000,00$ e $R \$ 2.000,00$ \\
\hline UBS Pactual S. A. & Estágiário & Entre $R \$ 2.000,00$ e $R \$ 3.000,00$ \\
\hline Correios e Telégrafos & Gerente de unidade de distribuição & Entre $R \$ 2.000,00$ e $R \$ 3.000,00$ \\
\hline Avina Brasil Serviços Ltda & Coordenador de controladoria & Entre $R \$ 2.000,00$ e $R \$ 3.000,00$ \\
\hline Fundação Vale do Rio Doce de Seguridade Social & Analísta de investimento & Entre $R \$ 2.000,00$ e $R \$ 3.000,00$ \\
\hline Canal de Marketing Promocional & Analísta de Marketing & Entre $\mathrm{R} \$ 2.000,00$ e $\mathrm{R} \$ 3.000,00$ \\
\hline Gaplog Logística e Transportes Ltda. & Sócio/gerente & Entre $R \$ 2.000,00$ e $R \$ 3.000,00$ \\
\hline Puc - Rio & Suporte financeiro e administrativo & Entre $R \$ 2.000,00$ e $R \$ 3.000,00$ \\
\hline Organizações Globo & Organizações Globo & Entre $R \$ 2.000,00$ e $R \$ 3.000,00$ \\
\hline Sociedade Comercial e Importadora Hermes S.A. & Gerente de vendas & Entre $\mathrm{R} \$ 4.000,00$ e $\mathrm{R} \$ 5.000,00$ \\
\hline Não informou & Não informou & Não informou \\
\hline
\end{tabular}

Fonte: Elaborada pelos autores.

$\mathrm{Na}$ análise dos resultados do grupo com maior renda familiar (acima de $\mathrm{R} \$ 12.000,00$ ), chama atenção o fato de $50 \%$ não estar trabalhando, incluindo-se nesse número tanto egressos, quanto formandos (tabela 1). Por se tratarem de indivíduos que, em sua maioria (91\%), moram com a família e possuem elevada renda familiar, essa condição parece sugerir que os detentores de maior capital econômico têm a possibilidade de escolher o trabalho ou o estágio mais adequado às suas expectativas, ao invés de possíveis dificuldades de inserção no mercado de trabalho (tabela 3). Por outro lado, os ocupados (estagiários ou funcionários) estão predominantemente inseridos em grandes empresas - em geral, multinacionais e empresas atuantes nos mercados financeiro e de consultoria -, recebendo remuneração superior a dos respondentes do grupo anterior. Deixando de lado os estagiários e observando-se a remuneração daqueles que já são empregados (15, no total), há seis indivíduos (40\%) recebendo entre $\mathrm{R} \$ 1.000,00$ e $\mathrm{R} \$ 3.000,00$ e sete (46\%) que recebem remuneração superior a $\mathrm{R} \$ 3.000,00$. Esse resultado contrasta com o do grupo anterior cujos percentuais, para as mesmas faixas salariais, são $91 \%$ e $8 \%$ respectivamente (tabelas 2 e 4 ).

Tabela 3

Grupo de indivíduos segundo a condição de moradia

\begin{tabular}{cccc}
\hline Renda familiar & Com quem mora? & Freqüência & \% \\
\hline \multirow{2}{*}{ Até $\mathrm{R} \$ 5.000,00$ (22 respondentes) } & Pais & 9 & - \\
\cline { 2 - 4 } & Pai e madrasta / mãe e padrasto & 2 & - \\
\cline { 2 - 4 } Acima de $\mathrm{R} \$ 12.000,00$ (42 respondentes) & Total & $\mathbf{1 1}$ & $\mathbf{5 0}$ \\
\cline { 2 - 4 } & Pai e madrasta / mãe e padrasto & 2 & - \\
\cline { 2 - 4 } & Total & $\mathbf{3 8}$ & $\mathbf{9 1}$ \\
\hline
\end{tabular}

Fonte: Elaborada pelos autores. 
Tabela 4

Grupo de indivíduos com maior renda familiar (acima de $R \$ 12.000,00$ )

\begin{tabular}{|c|c|c|}
\hline Empresa & Função & Renda própria \\
\hline Eletronuclear & Estágiário & Até $R \$ 1.000,00$ \\
\hline S. C. Johnson & Estágiário & Até $\mathrm{R} \$ 1.000,00$ \\
\hline Citibank & Estágiário & Até $R \$ 1.000,00$ \\
\hline Petros & Estagiário & Até $R \$ 1.000,00$ \\
\hline ATM 2 Marketing Direito & Consultor de vendas & Até $R \$ 1.000,00$ \\
\hline Vale & Estagiário & Até $R \$ 1.000,00$ \\
\hline Cinco & Ass. financeiro & Até $\mathrm{R} \$ 1.000,00$ \\
\hline IBM & Estágiário & Até $\mathrm{R} \$ 1.000,00$ \\
\hline Globosat & Estágiário & Até $\mathrm{R} \$ 1.000,00$ \\
\hline TIM & Não informou & Até $\mathrm{R} \$ 1.000,00$ \\
\hline Americanas.com - B2W Cia Global do Varejo & Estagiário & Entre $R \$ 1.000,00$ e $R \$ 2.000,00$ \\
\hline Accenture - Consultoria & Estágiário & Entre $R \$ 1.000,00$ e $R \$ 2.000,00$ \\
\hline Coca - Cola Brasil & Estágiário & Entre $\mathrm{R} \$ 1.000,00$ e $\mathrm{R} \$ 2.000,00$ \\
\hline Enseg & Estágiário & Entre $\mathrm{R} \$ 1.000,00$ e $\mathrm{R} \$ 2.000,00$ \\
\hline Newpark Drilling Fluids & Estágiário & Entre $R \$ 1.000,00$ e $R \$ 2.000,00$ \\
\hline EBN & Aux. administrativo & Entre $R \$ 1.000,00$ e $R \$ 2.000,00$ \\
\hline Autônomo & Tradutor & Entre $\mathrm{R} \$ 1.000,00$ e $\mathrm{R} \$ 2.000,00$ \\
\hline Casa e Vídeo & Ass. de compras & Entre $\mathrm{R} \$ 2.000,00$ e $\mathrm{R} \$ 3.000,00$ \\
\hline B2W - Companhia Global do Varejo & Comprador & Entre $R \$ 2.000,00$ e $R \$ 3.000,00$ \\
\hline $\mathrm{Ol}$ & Analísta de marketing I & Entre $R \$ 2.000,00$ e $R \$ 3.000,00$ \\
\hline Não informou & Comprador & Entre $\mathrm{R} \$ 2.000,00$ e $\mathrm{R} \$ 3.000,00$ \\
\hline UBS Pactual CTVM & Operador de bolsa - formadores de mercado & Entre $\mathrm{R} \$ 3.000,00$ e $\mathrm{R} \$ 4.000,00$ \\
\hline Programa Iniciativa Jovem (Shell - Dialog) & Coordenador de conhecimento & Entre $\mathrm{R} \$ 3.000,00$ e $\mathrm{R} \$ 4.000,00$ \\
\hline Brasil Brokers & Analísta pleno & Entre $R \$ 3.000,00$ e $R \$ 4.000,00$ \\
\hline Homacc - Comércio de Material Médico Ltda. & Gerente comercial & Entre $\mathrm{R} \$ 3.000,00$ e $\mathrm{R} \$ 4.000,00$ \\
\hline Pamela Saade Jewellery Design & Proprietário & Entre $\mathrm{R} \$ 4.000,00$ e $\mathrm{R} \$ 5.000,00$ \\
\hline Dollarama L.P. & Analísta de estoque & Acima de $R \$ 5.000,00$ \\
\hline Banco Brascan S.A. & Analista 2 & Acima de $R \$ 5.000,00$ \\
\hline
\end{tabular}

Fonte:Elaborada pelos autores.

O gráfico seguinte (figura 2) permite visualizar melhor as diferenças entre as remunerações dos indivíduos empregados nos dois grupos analisados. 


\section{Figura 2}

Gráfico com os percentuais das diferenças de remuneração dos indivíduos empregados nos dois grupos analisados

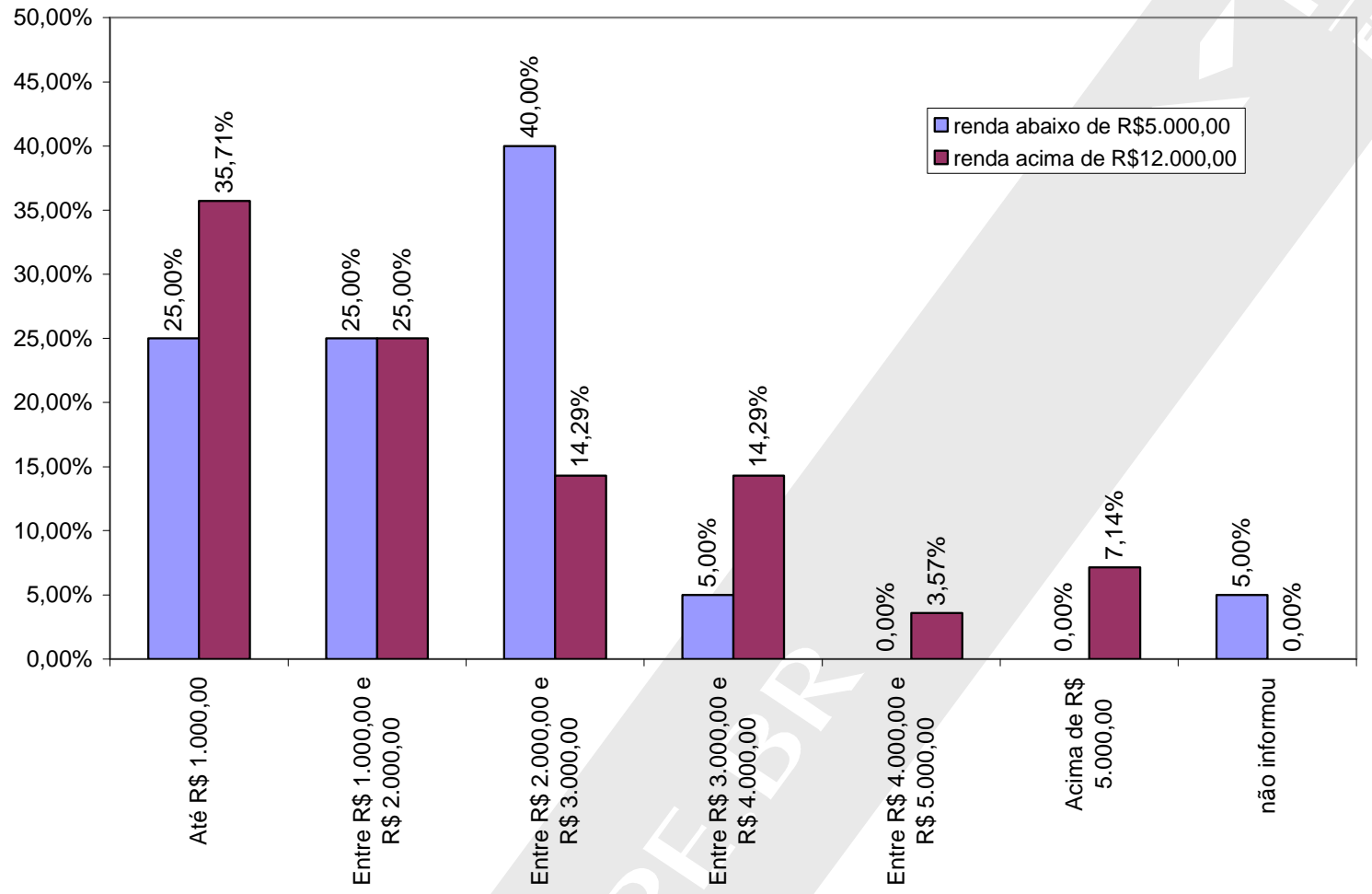

Fonte: Elaborada pelos autores.

Deve ser observada a situação de dois profissionais com renda familiar menor que recebem remunerações entre $\mathrm{R} \$ 2.000,00$ e $\mathrm{R} \$ 3.000,00$ e trabalham, respectivamente, nos Correios e Telégrafos e na Gaplog Logística, conforme consta na tabela 2. No primeiro caso, o indivíduo é funcionário de uma empresa estatal, à qual teve acesso por meio de concurso público. No segundo, o respondente é dono de sua própria empresa. Visto que em nenhuma das duas circunstâncias (concurso público e empreendedorismo) o impacto das relações sociais influencia diretamente em sua inserção profissional, mais adequado seria expurgá-los para fins de comparação. Optando-se por esse caminho, ficaria mais desfavorável a situação deste grupo diante daquele originário de famílias com maior renda.

Outro resultado observado, que reforça a afirmação de Bourdieu acerca das vantagens que os privilegiados economicamente desfrutam, diz respeito à forma como o respondente teve acesso ao atual emprego ou estágio. Enquanto cerca de dois terços dos indivíduos com menor renda informaram ter obtido a vaga atendendo a recrutamentos formais (anúncios de estágio/emprego, envio de currículos e concursos) e apenas 15\% contaram com indicações de conhecidos e familiares, os de maior renda, apesar de também terem recorrido a processos formais (46\%), contaram com a indicação de familiares e colegas (43\%), além de alguns trabalharem em negócios da família (11\%), oportunidade que não apareceu nas informações do primeiro grupo. A importância do capital social, conforme ressalta Bourdieu, potencializa as chances dos detentores de capital cultural (no 
caso, a formação superior) converterem em capital econômico a formação recebida. Os conhecimentos, as "relações mundanas" (BOURDIEU, 1988, p.118) são um recurso a mais, um capital adicional à disposição dos possuidores de maior capital econômico, o que confere a seus detentores melhores condições, do que ao grupo menos favorecido economicamente, de transformar a formação superior conquistada em capital econômico (figura 3). No caso em estudo, o recurso à rede de relacionamentos aparece como estratégia importante para o grupo com renda mais elevada, mas é periférico para o outro grupo.

\section{Figura 3}

Gráfico com os percentuais da forma de obtenção das informações/contatos sobre as oportunidades de emprego

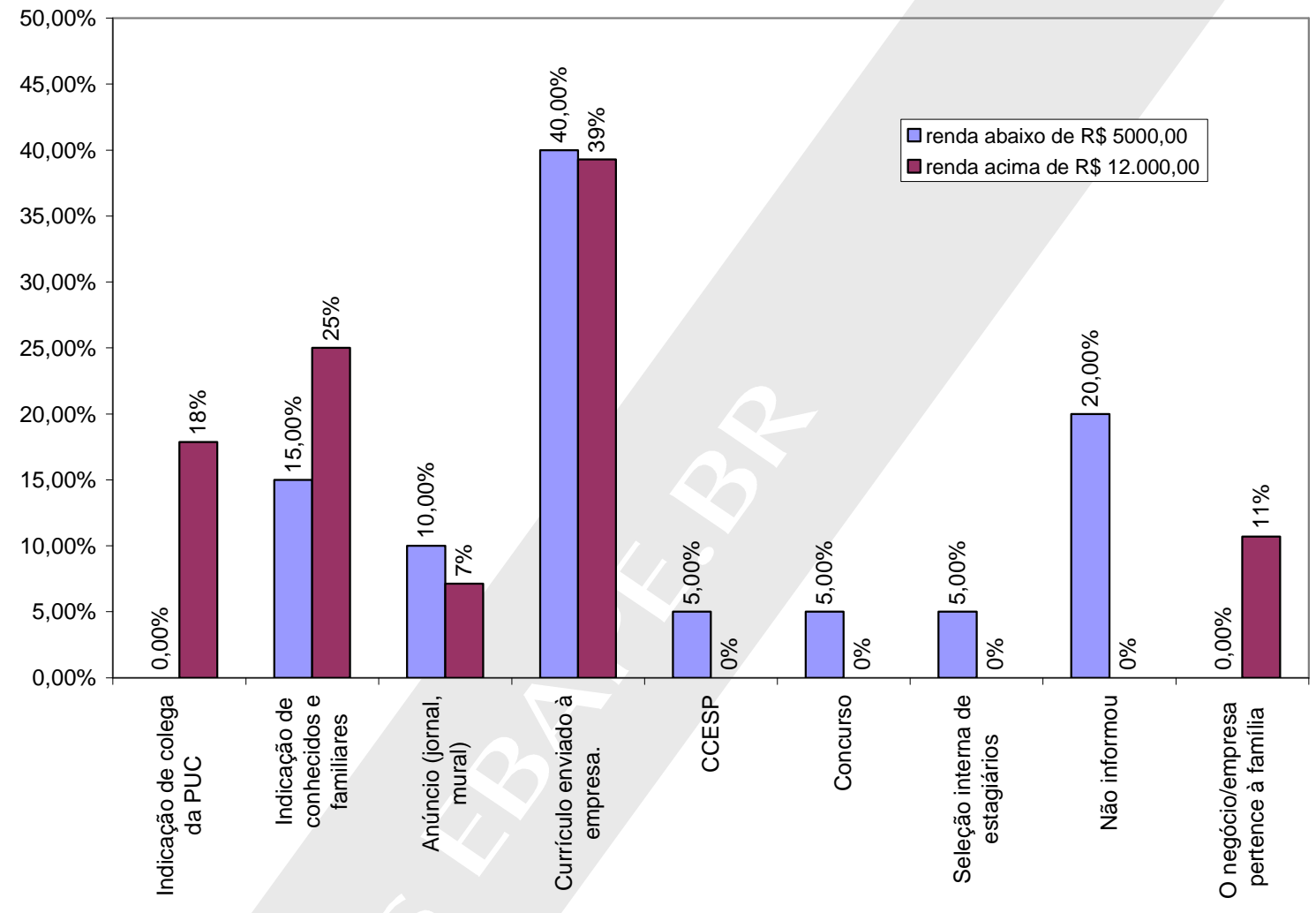

Fonte: Elaborada pelos autores.

É importante também ressaltar as diferenças de escolaridade dos pais dos respondentes. Conforme assevera Bourdieu, a educação formal dos pais é um importante indicador do capital cultural herdado pelo filho e, nesta pesquisa, tal fato revela-se de forma inequívoca. Enquanto nas famílias com maior renda, $81 \%$ dos pais possuem, pelo menos, um curso superior, não sendo raros os casos de pós-graduação, nas famílias com menor renda esses percentuais caem para $27 \%$ (figura 4). Cabe apontar, ainda, que cerca de $23 \%$ dos pais dos entrevistados oriundos de famílias com menor renda possuem, no máximo, o ensino fundamental completo. Esses dados configurariam, nos termos do autor, uma condição privilegiada para os primeiros, dado que os filhos das elites econômicas tendem a reproduzir a "vocação" (BOURDIEU, 1988, p.134) para carreiras universitárias dos pais. Apesar do desnível sensível entre a escolaridade dos pais dos dois grupos examinados, não pode passar despercebido, no entanto, o fato de $22 \%$ dos indivíduos egressos ou em vias de concluir um curso de graduação em uma universidade privada serem oriundos de famílias cujos pais possuem baixa 
escolaridade, o que indica, por outro lado, a possibilidade concreta de se romper com a "vocação" herdada dos pais, à qual se refere Bourdieu. Ademais, a ascensão cultural e econômica desses indivíduos, também pode ser vista como reforço ao argumento central dos defensores da teoria do capital humano, que apostam na educação como principal determinante das oportunidades de inserção no mercado de trabalho e da remuneração recebida.

Figura 4

Gráfico com percentuais indicativos da formação dos pais dos respondentes

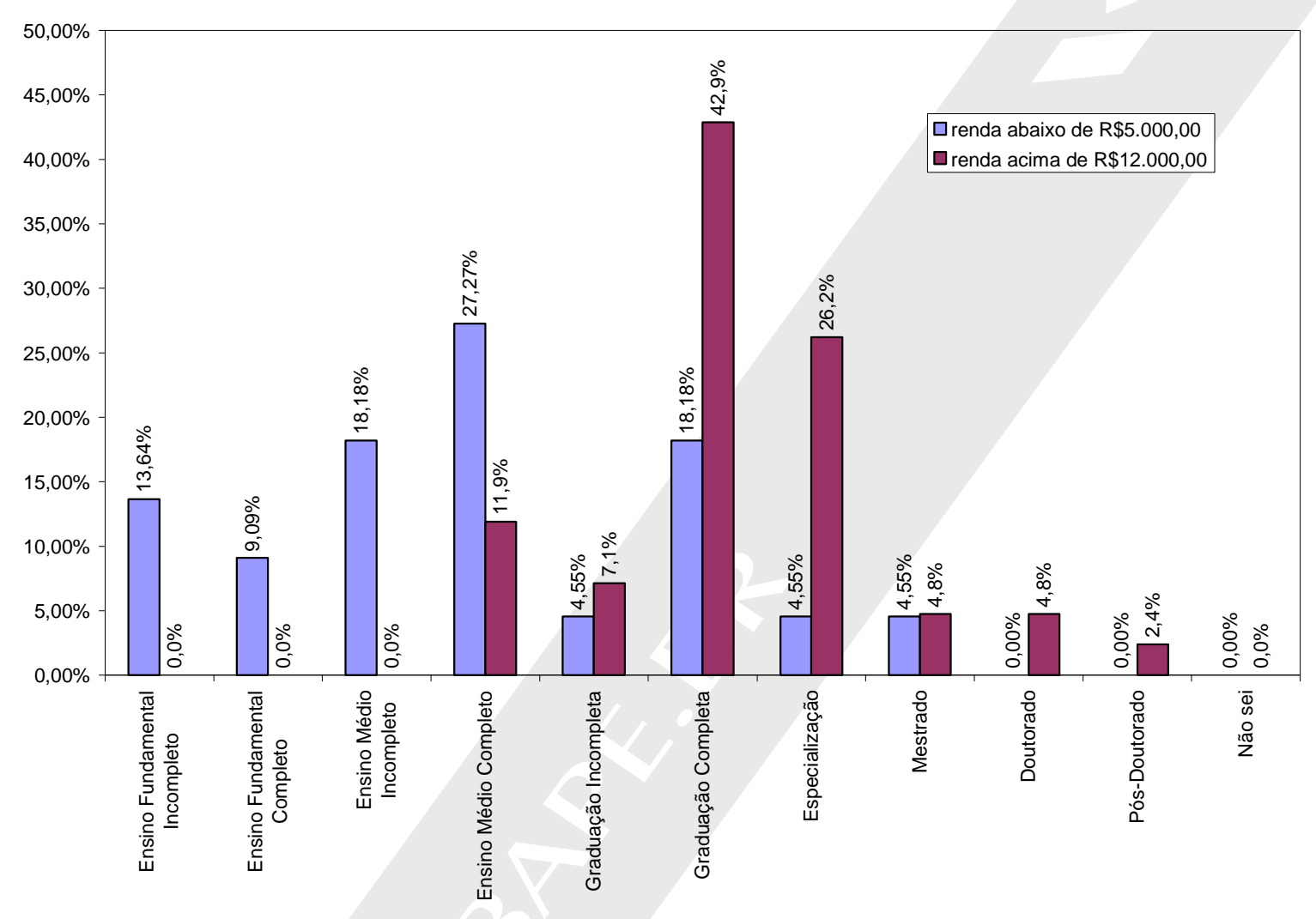

Fonte: Elaborada pelos autores.

As oportunidades diferenciadas que os possuidores de maior capital econômico desfrutam também são evidenciadas nos resultados do levantamento. Enquanto o hábito de viajar faz parte da rotina do primeiro grupo (98\%), o segundo viaja com menos freqüência (55\%). Viagens ao exterior também são rotineiras para os respondentes com maior renda (100\%), porém, são menos freqüentes entre os que possuem renda mais baixa (42\%) (tabelas 5 e 6). Em sintonia com as afirmações de Bourdieu, esse é outro ponto de desequilíbrio, pois tal oportunidade amplia o capital cultural do grupo detentor de maior capital econômico e social, aumentado seu diferencial competitivo vis-à-vis o grupo menos favorecido economicamente. Nesse sentido, pode-se postular que, apesar da aparente homogeneidade cultural dos respondentes - todos formandos ou egressos da mesma IES -, há diferenças culturais significativas no seio desse grupo, seja decorrente da mencionada exposição maior a viagens, seja decorrente da escolaridade maior de seus pais, em contraste com o outro grupo.

Essas diferenças tendem a produzir impacto na empregabilidade de seus detentores, conforme indicam os resultados da pesquisa realizada por Pinto e Lemos (2006) em empresas que dispõem de processos estruturados de contratação de trainees. Na referida pesquisa, destacou-se a importância dada pelos futuros empregadores à dimensão social daqueles que aspiram a cargos de gerência. Paralelamente à expectativa dos empregadores de 
que os indivíduos oriundos de classes sociais mais favorecidas tenham uma sólida formação acadêmica, há a certeza de que estes usufruem de redes de contato diferenciadas e experiências de vida relevantes aos negócios que gerenciarão.

Tabela 5

Dados sobre a pergunta: Você costuma viajar nas suas férias?

\begin{tabular}{ccccc}
\hline \multirow{2}{*}{ Respostas } & \multicolumn{2}{c}{ Até R\$5.000,00 } & \multicolumn{2}{c}{ Acima de R\$12.000,00 } \\
\cline { 2 - 5 } & Freqüência & \% & Freqüência & \% \\
\hline Sim & 12 & $54.55 \%$ & 41 & $97.62 \%$ \\
\hline Não & 8 & $36.36 \%$ & 0 & $0.00 \%$ \\
\hline $\begin{array}{c}\text { Não } \\
\text { informou }\end{array}$ & 2 & $9.09 \%$ & 1 & $2.38 \%$ \\
\hline Total & 22 & $100.00 \%$ & 42 & $100.00 \%$ \\
\hline
\end{tabular}

Fonte:Elaborada pelos autores.

Tabela 6

Dados sobre a pergunta: Você já esteve no exterior?(respostas múltiplas)

\begin{tabular}{ccc}
\hline Respostas & Até R\$5.000,00 & Acima de R\$12.000,00 \\
\hline Nunca estive no exterior & $57,14 \%$ & $0,00 \%$ \\
\hline Estive no exterior a passeio & $23,81 \%$ & $42,22 \%$ \\
\hline Estive no exterior fazendo intercâmbio & $14,29 \%$ & $20,00 \%$ \\
\hline Morei no exterior com minha família & $0,00 \%$ & $8,89 \%$ \\
\hline Viajo regularmente ao exterior & $4,76 \%$ & $28,89 \%$ \\
\hline Total & $100 \%$ & $100 \%$ \\
\hline
\end{tabular}

Fonte: Elaborada pelos autores.

Não obstante as diferenças percebidas entre as condições de inserção dos respondentes de maior e menor renda, deve-se ressaltar que, por sua natureza sutil, seria impreciso considerá-las como evidências a corroborar a tese de Bourdieu acerca das reproduções das desigualdades sociais. Entretanto, entende-se que essas constatações sinalizam a pertinência de se aprofundar pesquisas capazes de explorar, ainda mais, as conclusões do referido autor, pois, se é fato que, para a amostra pesquisada, as diferenças das condições de inserção no mercado de trabalho entre detentores de maior e menor capital econômico podem não ser definitivas, também é verdadeiro afirmar que os resultados apresentados estão longe de indicar uma homogeneidade nesses dois grupos. Ao contrário, conforme foi assinalado, a julgar pela amostra analisada, há diferenças perceptíveis tanto no que tange à remuneração quanto no que diz respeito ao tipo de vaga obtida, pois as grandes empresas 
multinacionais citadas na pesquisa empregam mais indivíduos oriundos de famílias com maior renda do que indivíduos economicamente menos favorecidos.

\section{Recomendações para futuras pesquisas}

Não obstante a relevância das constatações resultantes do levantamento apresentado, conforme anteriormente ressaltado, o curso de administração de empresas da IES pesquisada caracteriza-se por receber alunos oriundos de famílias com renda elevada (capital econômico, nos termos de Bourdieu), o que, apesar de não comprometer, enviesa esta análise. Por esse motivo, está nos planos dos autores investigar grupos de egressos/formandos mais heterogêneos economicamente. $\mathrm{O}$ estudo desses indivíduos permitirá aprofundar, corroborar ou refutar as conclusões deste artigo. Ademais, possibilitará intensificar o debate, tanto à luz da tese de Bourdieu acerca da reprodução das desigualdades sociais, quanto diante da premissa central da teoria do capital humano de que a educação é a principal determinante da situação socioeconômica do indivíduo. Outro encaminhamento que enriquecerá futuras pesquisas será a ampliação temporal da pesquisa, incorporando à amostra, egressos formados há mais tempo. Com isso, será possível visualizar a evolução de sua empregabilidade, dado que, no intervalo de um ano considerado nesta pesquisa, as condições distintas de competitividade dos participantes podem ainda não ter se materializado completamente. 


\section{Referências}

BOURDIEU, Pierre. La distincion. Madrid: Taurus, 1988.

BANCO MUNDIAL. Relatório sobre o desenvolvimento mundial 1995: o trabalhador e o processo de integração mundial. Washington, D.C., 1995.

CAMARGO, José Márcio; ALMEIDA, Heitor. Human capital investment and poverty. Rio de Janeiro: PUC-Rio, maio 1994. (Texto para Discussão, n.319).

CASTELLS, Manuel. A sociedade em rede. São Paulo: Paz e Terra, 1999.

DEDECCA, Cláudio. Qualificação e formação profissional: algumas experiências européias. In: A VISÃO empresarial e da universidade do Plano Nacional de Educação Profissional. São Paulo: Instituto Uniemp, 1998. v.2.

DRUCKER, Peter. Sociedade pós-capitalista. São Paulo: Pioneira, 1999.

FERREIRA, Francisco. Os determinantes da desigualdade de renda no Brasil: luta de classes ou heterogeneidade educacional? Rio de Janeiro: PUC-Rio, 2000. (Texto para Discussão, n.415).

FRIGOTTO, Gaudêncio. Educação, crise do trabalho assalariado e do desenvolvimento: teorias em conflito. In: FRIGOTTO, Gaudêncio (Org.). Educação e crise do trabalho: perspectivas de final de século. Petrópolis: Vozes, 2001a.

. Educação e formação humana: ajuste neoconservador e alternativa democrática. In: GENTILI, Pablo; SILVA, Tomaz (Org.). Neoliberalismo, qualidade total e educação. Petrópolis: Vozes, 2001b.

. Os delírios da razão: crise do capital e metamorfose conceitual no campo educacional". In: GENTILI, Pablo (Org.). Pedagogia da exclusão: críticas ao neoliberalismo em educação. Petrópolis: Vozes, 2001c.

GENTILI, Pablo. O conceito de empregabilidade. In: SEMINÁRIO NACIONAL SOBRE AVALIAÇÃO DO PLANFOR: uma política pública de educação profissional em debate, 4-5 mar. 1999, São Carlos. Anais... São Paulo: Unitrabalho, 1999.

Educar para o desemprego: a desintegração da promessa integradora. In: FRIGOTTO, Gaudêncio (Org.). Educação e crise do trabalho: perspectivas de final de século. Petrópolis: Vozes, 2001.

GRAZIER, Bernard. L'emploeabilitié: brève radiographie d"un concept en mutation. Sociologie du Travail, n.4, 1990.

OIT - Organização Internacional do Trabalho. Perspectivas para o futuro. In: ABERTURA e ajuste do mercado de trabalho no Brasil. Políticas para conciliar os desafios de emprego e competitividade. Brasília, DF: OIT/MTE, 1999.

PAIVA, Vanilda. O novo paradigma de desenvolvimento: educação, cidadania e trabalho. Educação e Sociedade, n.45, p.309-326, ago. 1993.

PINTO, M; LEMOS, A. H. Empregabilidade dos administradores: quais os perfis profissionais que vêm sendo demandados pelas empresas: In: ENCONTRO NACIONAL DE PROGRAMAS DE PÓS-GRADUAÇÃO EM ADMINISTRAÇÃO - ENANPAD, 30., 2006, Salvador. Anais... [S.I.: s.n.]. CD-ROM.

RAMOS. Curso superior garante emprego? O Globo, Rio de Janeiro, p.31, 12/11/2006.

SCHULTZ, Theodore. O valor econômico da educação. Rio de Janeiro, Zahar, 1967.

. Investindo no povo. Rio de Janeiro: Forense-Universitária, 1987.

SOARES, Rodrigo Reis; Gustavo GONZAGA. Determinação de salários no Brasil: dualidade ou não-linearidade no retorno à educação? Rio de Janeiro: Ipea, dez. 1997. (Texto para Discussão, n.38).

TOFFLER. Alvin. Powershift: as mudanças do poder. Rio de Janeiro: Record, 1998. 